\title{
GESTÃO DE CUSTOS A PARTIR DE UMA ANÁLISE DE TEMPOS E MOVIMENTOS: Estudo de caso em uma metalúrgica
}

\author{
Matheus Lima Medeiros (Unifavip) matheusmedeiros@outlook.pt
}

\section{RESUMO}

Os desafios enfrentados diariamente dentro das organizações vêm exigindo uma maior manutenção dentro do mundo empresarial. Em buscar de se adequar ao mercado, as empresas vêm utilizando a gestão de custos, onde é possível mensurar os gastos de cada departamento, analisar as despesas e receitas, além de verificar possíveis prejuízos dentro da organização. Esse estudo foi desenvolvido em uma metalúrgica em Caruaru-PE, onde foi necessário identificar o fluxo produtivo e iniciar um estudo de tempos e movimentos para mensurar a capacidade produtiva, em sequência foi necessário calcular o custo de cada setor da empresa e por fim somar a margem de contribuição e o lucro que a empresa deseja receber com seus produtos. Foi identificado gargalos durante o desenvolvimento do estudo, e sugestões de melhorias para a redução de tempo de produção e otimização do processo.

Palavras-Chaves: Gestão de Custos; Metalúrgica; Tempos e Movimentos.

\section{INTRODUÇÃO}

O mercado competitivo vem buscando uma excelência operacional dentro das empresas, focando na redução de despesas, melhorando seus processos, sempre em busca de crescimento. A gestão de custos vem sendo uma excelente metodologia dentro das organizações para se traçar um planejamento estratégico e ficar à frente dos seus concorrentes.

Este trabalho é um estudo de caso que tem como objetivo analisar e mensurar o custo de um produto em toda a linha de produção em uma empresa metalúrgica, tradicional fabricante de produtos em aço, localizada no interior do estado de Pernambuco a partir de um estudo de cronoanálise para estimar a capacidade produtiva da empresa.

Inicialmente será apresentado uma revisão de literatura a respeito sobre a metodologia de tempos e movimentos e gestão de custos, seguido de uma descrição sobre o fluxo produtivo da empresa e a cálculo de custo de cada etapa do processo produtivo, por fim, a sugestão de melhorias e as considerações finais do artigo. 


\section{FUNDAMENTAÇÃO TEÓRICA}

\subsection{Estudo de tempos e movimentos}

A partir do século xx, apresentadas por Frederick Taylor, as técnicas de estudo de tempos foram utilizadas a partir de métodos estatísticas, sendo utilizada exclusivamente em fábricas industriais. Frederick W. Taylor é conceituado por esse motivo o pai da administração científica.

Segundo Barnes (1977) o estudo de tempos, introduzido por Taylor, foi usado principalmente na determinação de tempos-padrão e o estudo de movimentos, desenvolvido pelo casal Gilbreth, foi empregado na melhoria de métodos de trabalho. Com isso, foi possível surgir a engenharia de métodos, onde um dos princípios básicos foi o estudo dos tempos e movimentos.

A finalidade de definir o tempo padrão de uma tarefa consegue oferecer pelo menos dois grandes benefícios, afirma Moreira (1993). A primeira compreende a possibilidade de poder estimar, pela redução ou não do tempo, se ocorreu melhoramento no método de trabalho a partir de um estudo já realizado de métodos. Já o segundo benefício consiste que ele serve como base para posteriormente determinar o custo industrial associado a um produto.

\subsubsection{Cálculo do tempo de eficiência}

Se for levada em consideração uma jornada de trabalho, os operadores se deparam com algumas interrupções que acontecem durante a jornada. Assim, a tolerância se firma como uma perda de tempo necessária para que o colaborador realize a tarefa em um ritmo normal estendido de pausas involuntárias. Barnes (1977) classifica as pausas em três, que são mostradas no quadro 1 a seguir. 


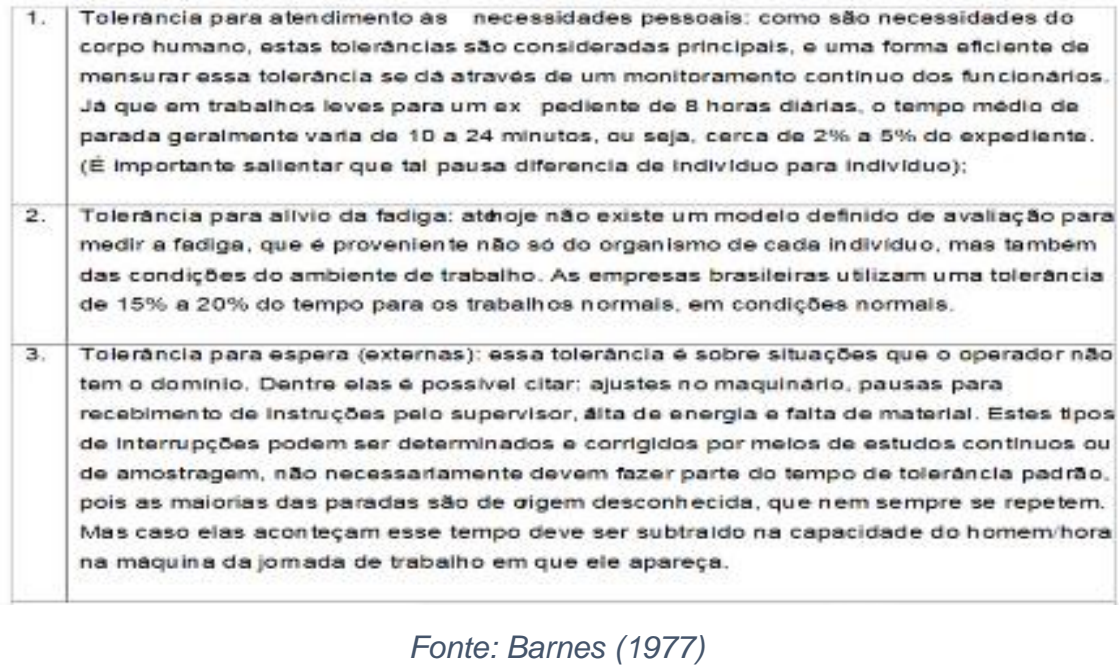

A utilização de tolerância na empresa é baseada a partir dos tempos de permissão que ela está disposta a aceitar através do seu índice de eficiência determinado para uma jornada de trabalho. Com isso, deve-se somar a eficiência e, em seguida, calcular o fator de tolerância.

\subsubsection{Cálculo da capacidade produtiva}

A capacidade de produção é uma tarefa difícil, visto que as políticas da empresa, o alinhamento com os fornecedores, a confiabilidade dos equipamentos, taxas de produção, bem como o impacto dos fatores humanos integrados à variabilidade agem sobre tais sistemas.

Para Slack (2002) a capacidade produtiva é definida como “o máximo nível de atividade de valor adicionado em determinado período que o processo pode realizar sob condições normais de operação". Segundo Ritzman (2004), para a empresa continuar se mantendo competitiva no mercado, mantendo os clientes satisfeitos e conseguindo atender sua demanda de forma adequada, é necessário obter a capacidade produtiva de todos os setores da empresa, visto que há uma integração entre setores, que de nada adianta a empresa ter um setor atuando com sucesso se no próximo posto de trabalho existe um que não se consegue produzir a tempo, gerando atrasos em todos os processos seguintes.

\subsection{Gestão de Custos}

A gestão de custos é fundamental dentro da organização, a partir dela, é possível saber o gasto dos produtos/serviços que a organização produz, sendo fundamental dentro de 
qualquer organização essa gestão. Segundo Bruni e Famá (2003), além do rigoroso conhecimento e comando dos custos de produção, é essencial identificar as possibilidades de melhorias de processos que resultem na identificação e eliminação de desperdícios que elevam o custo da produção e reduzem a lucratividade ou a competitividade das empresas. Para Kunh et al. (2011) o gerenciamento dos custos tem como principais objetivos auxiliar no planejamento e verificar o desempenho da empresa através do conhecimento do custo unitário dos produtos, sendo esse obtido através da contabilidade de custos. Ela é essencial para a tomada de decisões relacionadas ao ambiente externo, onde existe um mercado com alto nível de competitividade.

\subsubsection{Classificações dos Custos}

A classificação dos custos pode ser analisada sob dois aspectos: quanto ao volume de produção podemos classificar como fixos e variáveis. Quanto aos produtos, podemos classificar os custos em diretos e indiretos. Segundo Buvinich (2014) são classificados em:

- Fixos: São custos que, não variam a partir do volume de atividade da empresa. São aqueles que existem independentemente da quantidade produzida.

- Variáveis: Seu valor total altera-se diretamente em função da ocupação da organização. Logo, varia de acordo com o volume da produção.

- Diretos: São os custos de fácil alocação aos produtos, sendo esse diretamente incluídos no cálculo. Apresentam a característica de serem mensuráveis de forma objetiva.

- Indiretos: São os custos de difícil alocação aos produtos/serviços e necessitam de aproximações, isto é, algum critério de rateio, para serem atribuídos aos produtos.

Segundo MARTINS (2008), "um método de custeio é diferente do outro no que se refere ao que é considerado como custo do produto em contraposição ao que é tratado como encargo do período. Nesse sentido é necessário identificar quais são os custos fixos e variáveis".

\subsubsection{Margem de contribuição}

A Margem de Contribuição cria uma relação entre custo e lucro. O conceito é 
especialmente útil no planejamento empresarial porque fornece informações sobre o potencial lucro da empresa. Wernke (2005) fala que a expressão margem de contribuição constitui o valor resultante da venda de um item após serem deduzidos, do preço de venda respectivo, os custos e despesas variáveis (como matérias-primas, tributos incidentes sobre a venda e comissão dos vendedores) associados ao produto comercializado. A margem de contribuição pode ser conceituada como o valor (em $\mathrm{R} \$$ ) que cada item comercializado contribua para, inicialmente, pagar os custos fixos mensais da empresa e, posteriormente, gerar o lucro para organização.

\section{PROCEDIMENTOS METODOLÓGICOS}

O presente artigo foi realizado em uma indústria metalúrgica, onde são produzidos itens para a área de lojas de serviços. Para o início do estudo, a empresa requisitou um produto para servir como modelo do trabalho, o produto mais vendido de um dos seus setores, o cesto $\mathrm{n}^{\circ} 1$ que é produzido na tela. A partir disso, foi necessário realizar o mapa do fluxo produtivo, em sequência iniciar o estudo de tempos e movimentos para medi a capacidade produtiva, reunir informações com o setor de compras, financeiro e contabilidade da empresa para mensurar o custo de cada parte do processo, fazer o rateio do custo indireto e por fim acrescentar margem de contribuição.

\section{APLICAÇÃO E RESULTADOS}

\subsection{Processo da Empresa}

Após definir o produto e o setor, foi necessário identificar o fluxo produtivo do cesto, inicialmente foi identificado que a produção do setor é feita por lotes.

O setor da Tela é formado por 8 pessoas e 1 encarregado. O Cesto $\mathrm{N}^{\circ} 1$, é um produto que passa por toda a linha de produção do setor e diferente de alguns outros produtos, apenas produzido no mesmo, sem dependência de outras áreas de produção da empresa. Abaixo segue imagem do produto. 


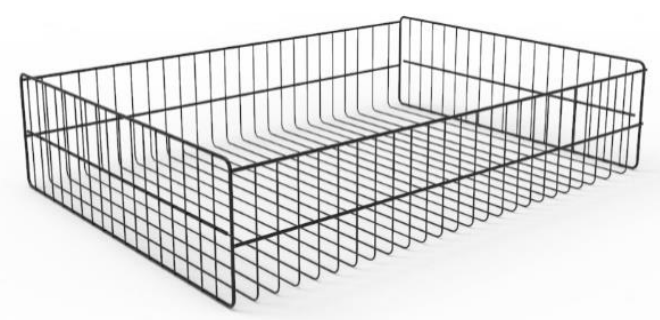

Fonte: Disponível pela empresa (2019)

\subsection{Tempos e Movimentos}

O estudo de tempos e movimentos foi iniciado direcionado ao setor de produção onde a maior parte dos processos é feito de forma manual, como, soldar topo, gabaritar, pontear, tirar rebarba, virada e montagem, todos esses processos citados é feito especificadamente no setor de tela. Abaixo, segue foto de um dos processos no setor.

Figura 2 - Operador ponteando Tela

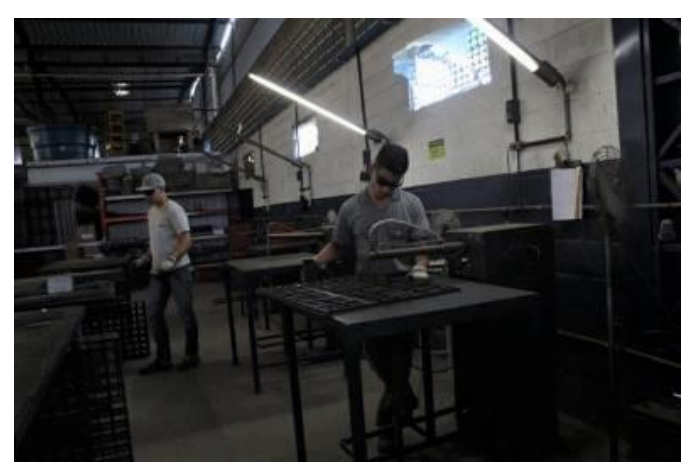

Fonte: Autor (2019)

Para desenvolver o estudo de custos, teria que iniciar identificando a capacidade de produção do cesto $\mathrm{n}^{\circ} 1$, para critério de rateio.

A princípio foi identificado os processos manuais de produção do produto e descrito no quadro 2.

Quadro 2 - Descrição dos processos do Cesto №1

\begin{tabular}{|c|c|}
\hline \multirow{2}{*}{ Op } & Item: Cesto $\mathrm{N}^{\circ} 1$ \\
\hline & Elementos de Trabalho \\
\hline 1 & GABARITAR FUNDO DO CESTO Nº1 \\
\hline 2 & PONTEAR FUNDO DO CESTO N¹ \\
\hline 3 & TIRAR RERBARBA DO FUNDO DO CESTO Nº1 \\
\hline 4 & VIRAR FUNDO DO CESTO N¹ \\
\hline 5 & SOLDAR TOPO DA LATERAL DO CESTO N¹ (2x) \\
\hline 6 & GABARITAR LATERAL DO CESTO N¹ (2x) \\
\hline 7 & PONTEAR LATERAL DO CESTO No1 (2x) \\
\hline 8 & TIRAR REBARBA DA LATERAL DO CESTO No1 (2x) \\
\hline 9 & MONTAGEM (2 LATERAIS + FUNDO) DO CESTO N¹ \\
\hline
\end{tabular}

Fonte: Autor (2019) 
O cesto $\mathrm{N}^{\circ} 1$ é composto por três partes, são duas laterais e um fundo, que com um auxílio de um gabarito, consegue unir essas partes e dar origem ao cesto. Foi preciso fazer um estudo de cronoanálise de cada processo, anotando cada tempo e preenchendo em uma tabela no Software Excel (2016) onde ela informa alguns parâmetros de cada processo. Após esses dados, o tempo de produção é dado entre a média do tempo máximo e do tempo padrão. O Quadro abaixo mostra os dados.

Quadro 3 - Tabela dos tempos e movimentos

\begin{tabular}{|c|c|c|c|c|c|c|c|c|c|c|c|c|c|c|c|}
\hline Item: Cesto $\mathrm{N}^{0} 1$ & & & emp & 0 & e 0 & bera & dor & & & & & & & & \\
\hline Elementos de Trabalho & & & & pos & Obser & vado & & & & & Máx & Mín & Med & Padrão & $\begin{array}{l}\text { Tempo de } \\
\text { Producão }\end{array}$ \\
\hline GABARTAR FUNDO DO CESTO No1 & 109 & 118 & 116 & 118 & 97 & 99 & 84 & 114 & 95 & 119 & 119 & 84 & 106,9 & 111,2 & 115 \\
\hline PONTEARFUNDO DO CESTO No1 & 122 & 121 & 135 & 114 & 113 & 121 & 132 & 123 & 115 & 126 & 135 & 113 & 122,2 & 127,1 & 131 \\
\hline TIRAR RERBARBA DO FUNDO DO CESTO No1 & 38 & 40 & 40 & 32 & 35 & 35 & 34 & 34 & 40 & 34 & 40 & 32 & 36,2 & 37,6 & 39 \\
\hline VIRAR FUNDO DO CESTO No1 & 18 & 16 & 15 & 18 & 16 & 14 & 16 & 15 & 18 & 18 & 18 & 14 & 16,4 & 17,1 & 18 \\
\hline SOLDAR TOPO DA LATERAL DO CESTO No1 (2x) & 38 & 36 & 38 & 36 & 40 & 38 & 38 & 34 & 44 & 46 & 46 & 34 & 38,8 & 40,4 & 43 \\
\hline GABARTAR LATERAL DO CEST0 N01 (2x) & 108 & 84 & 110 & 96 & 114 & 84 & 100 & 104 & 90 & 90 & 114 & 84 & 98,0 & 101,9 & 108 \\
\hline PONTEAR LATERAL DO CESTO N01 (2x) & 62 & 66 & 66 & 66 & 74 & 64 & 62 & 64 & 56 & 58 & 74 & 56 & 63,8 & 66,4 & 70 \\
\hline TIRAR REBARBA DA LATERAL DO CESTO N121 (2x) & 24 & 20 & 20 & 22 & 26 & 24 & 24 & 20 & 22 & 22 & 26 & 20 & 22,4 & 23,3 & 25 \\
\hline MONTAGEM (2 LATERAIS + FUNDO) DO CESTO No1 & 66 & 72 & 75 & 66 & 77 & 77 & 70 & 73 & 70 & 69 & 77 & 66 & 71,5 & 74,4 & 76 \\
\hline
\end{tabular}

Fonte: Autor (2019)

Continuando o estudo, foi preciso calcular as tolerâncias dos processos. Após pesquisas, foi determinado que o índice de produtividade é de 90\%. São disponibilizados 31800 segundos por dia para a operação, já retirando todas as paradas. No setor da tela como já informado são oito operadores, onde dois operadores ficam responsáveis por pontear, e dois por gabaritar, um fica responsável por montar o cesto, um operador por soldar topo e virada, um operador para tirar rebarba e um para fornecer os arames. Fazendo um balanceamento, é possível conseguir calcular a capacidade produtiva atual do setor, como mostra o resultado abaixo.

Quadro 4 - Quadro de capacidade produtiva

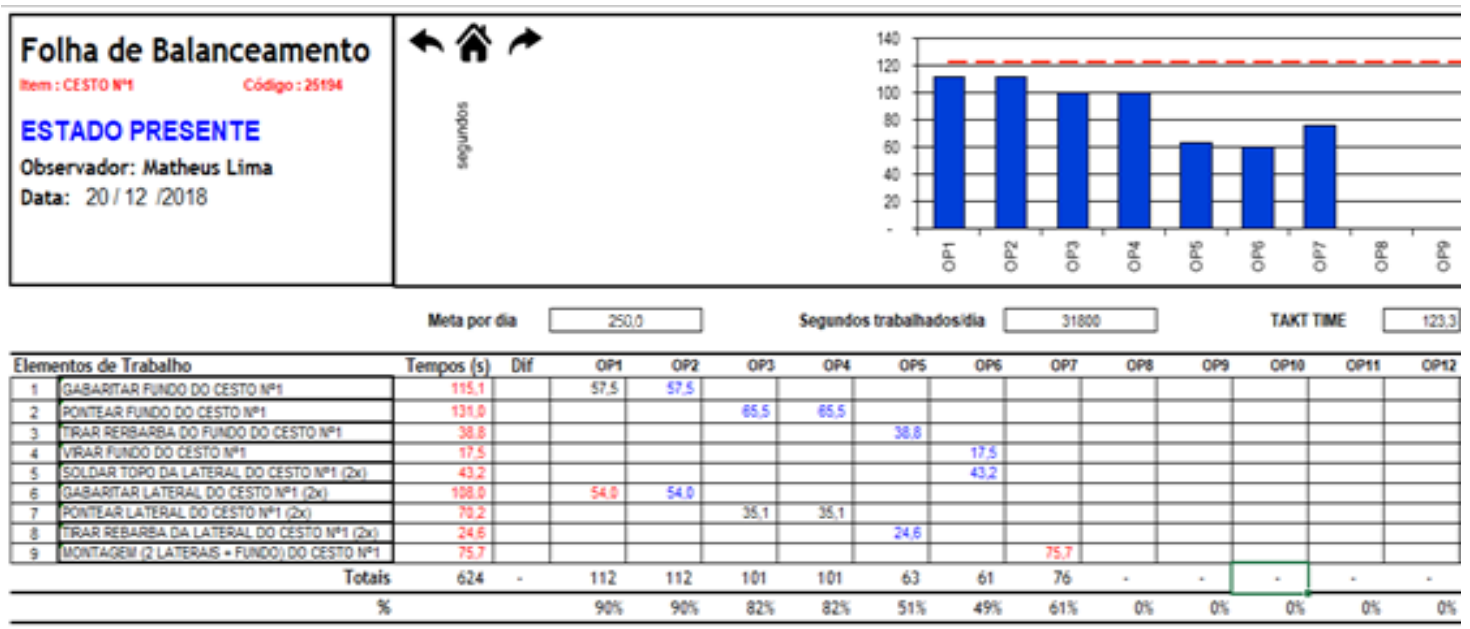

Fonte: Autor (2019) 
Como analisado na imagem, a produção diária do cesto ${ }^{\circ} 1$ atualmente é de 250 cestos por dia, na tabela acima é mostrado um gráfico onde percebesse que o gargalo na produção desse produto é nos processos de gabaritar e pontear o produto.

A partir da quantidade de dias disponíveis que a empresa considera, a capacidade produtiva mensal seria de cinco mil cestos, caso a empresa tivesse demanda para esse produto e optasse por produzi-lo durante um mês inteiro.

\subsection{Custos do Cesto}

Logo após identificar a capacidade produtiva do produto, foi preciso fazer uma análise e começar a desenvolver uma planilha para sintetizar cada custo presente no cesto. Abaixo segue os custos do item que precisaram ser identificados.

- Custo da Matéria Prima do Cesto;

- Custo com mão de obra de Produção;

- Custo com mão de obra de Pintura;

- Custo com mão de obra da Embalagem;

- Custo com a Tinta;

- Custo com a Embalagem;

- Custo com as Despesas Administrativas.

\subsubsection{Custo da Matéria Prima do Cesto}

Para se dar início ao custo do produto, foi necessário primeiramente saber quanto de matéria prima é utilizada, foi solicitar ao setor de design a vista explodida do produto, para saber o material utilizado. A figura 7 informa os dados necessários:

\section{Figura 3 - Desenho Técnico do Produto}

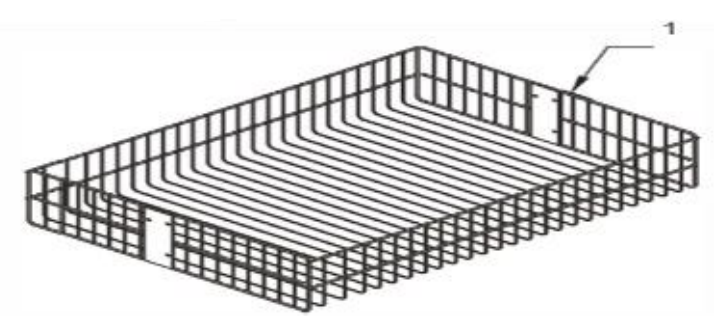




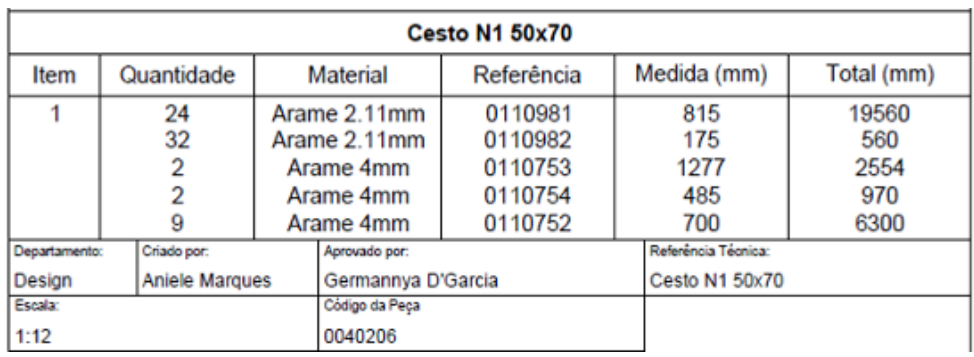

Fonte: Disponibilizado pelo setor de Design (2019)

Após a identificação dos materiais, foi preciso entrar em contato com o setor de compras, para fornecer o preço de cada insumo, porém, o preço é dado em quilo e o setor de design informa em milímetros, então foi preciso fazer a conversão de todos os valores para metros. Abaixo segue uma tabela para auxiliar nessa situação:

Quadro 5 - Conversão de Arames de quilo para cada metro

\begin{tabular}{|c|c|c|c|}
\hline \multicolumn{4}{|c|}{ ARAME } \\
\hline BITOLA & G / METRO & KG / METRO & $\mathrm{R} \$ /$ KG \\
\hline 2.11 & 29,4 & 0,0294 & $\mathrm{R} \$ 6,76$ \\
\hline 2.76 & 50 & 0,0500 & $\mathrm{R} \$ 6,76$ \\
\hline 4.00 & 100 & 0,1000 & $\mathrm{R} \$ 6,20$ \\
\hline 6.00 & 214,3 & 0,2143 & $\mathrm{R} \$ 6,20$ \\
\hline
\end{tabular}

Fonte: Disponibilizado pelo setor de Compras (2019)

Com esses dados, já foi possível calcular o peso, além do custo de insumos utilizados no produto. Com todas essas informações, começou a se desenvolver uma planilha, atrelado aos outros custos, informasse o custo total do produto.

Quadro 6 - Custo dos insumos

ARAMES INDUSTRAIS

\begin{tabular}{|c|c|c|c|c|c|c|}
\hline DESCRICÃo & BITOLA & KG/Metro & ALTURA (m) & QUANT. & R\$/KG & TOTAL \\
\hline A1 & 4.00 & 0,100 & 0,70 & 9 & $\mathrm{R} \$ 6,20$ & $\mathrm{R} \$ \quad 3,91$ \\
\hline A2 & 4.00 & 0,100 & 1,28 & 2 & $R \$ 6,20$ & $R \$ \quad 1,58$ \\
\hline A3 & 4.00 & 0,100 & 0,49 & 2 & $R \$ 6.20$ & $\mathrm{R} \$ \quad 0,60$ \\
\hline A4 & 2.11 & 0,029 & 0,82 & 24 & $R \$ 6,76$ & R\$ 3,89 \\
\hline A5 & 2.11 & 0,029 & 0,18 & 32 & $R \$ 6,76$ & $\mathrm{R} \$ \quad 1,11$ \\
\hline A6 & & & & & $\mathrm{R} \$$. & R\$ - \\
\hline A7 & & & & & $R \$$. & $\mathrm{R} \$-$ \\
\hline A8 & & & & & $\mathrm{R} \$$. & $R \$$ \\
\hline A9 & & & & & RS. & R\$ - \\
\hline A10 & & & & & RS. & $R \$$ \\
\hline & & TOTAL & 3,452 & 69 & TOTAL & $R \$ 11,09$ \\
\hline
\end{tabular}

40031 CUSTO DO ARAYE

\begin{tabular}{l|l|l|} 
SUB-TOTAL & RS 11,09 \\
\hline
\end{tabular}

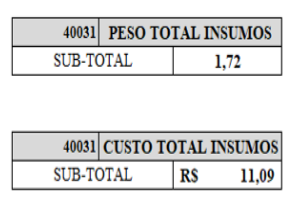

Fonte: Autor (2019)

\subsubsection{Custo da Mão de obra de produção do Cesto}

Continuando, foi preciso calcular o valor que a mão de obra que produzia o cesto, custava para esse produto e com isso foi solicitado ao setor financeiro qual seria o valor da hora 
trabalhada já que quanto mais tempo um produto leva a ser produzido, maior é o custo de mão de obra para esse mesmo.

O setor financeiro informou o valor somando todos os encargos. Valor esse que representa apenas os operadores do setor de tela que se envolvem diretamente no processo de construção do cesto.

Esse valor é calculado a partir dos tempos e movimentos, pois se sabe com maior precisão o tempo que é levado em cada processo desse produto e quanto cada operador custa para fazer esse processo. A partir da capacidade produtiva mensal do produto, é informado também o valor que a mão de obra custaria para se fabricar essa capacidade e após isso a planilha calcula o custo unitário de cada Cesto $\mathrm{N}^{\circ} 1$. Podemos mensurar isso que foi dito abaixo:

Quadro 7 - Custo da mão de obra de Produção

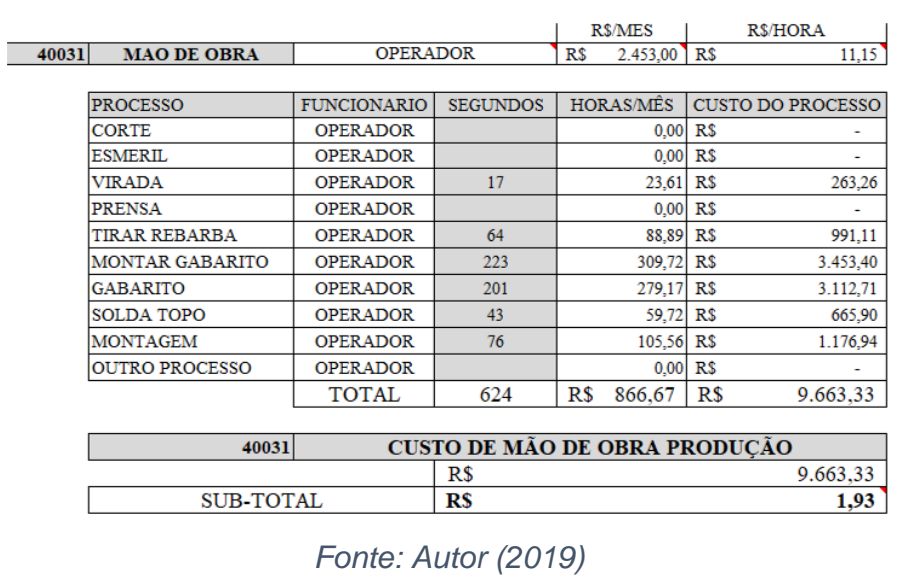

\subsubsection{Custo do Setor da pintura}

Após o produto montado, a ordem de produção informa a cor do item e nesse setor os custos se dividem em duas vertentes:

- Mão de Obra

- Tinta

\subsubsection{Custo da Mão de Obra no setor da Pintura}

Nesse setor, é desenvolvido o custo a partir do ritmo da máquina, o produto é movido por uma esteira com 320 gancheiras onde o produto é colocado. Essa máquina tem um forno onde o produto tem que ser passado por lá para ser aquecido. Após a pintura, esse produto gira mais uma vez na máquina para ser esquentado e depois retirado da linha, com isso, 
o produto é necessário girar duas vezes na máquina para se sair pronto. Esse processo é chamado de Pintura eletrostática onde é dado uma maior qualidade ao produto, além de uma camada mais resistente de tinta, evitando destaques e agregando maior valor ao produto. A figura consegue mostrar esse processo:

Figura 4 - Linha de Produção do setor da Pintura

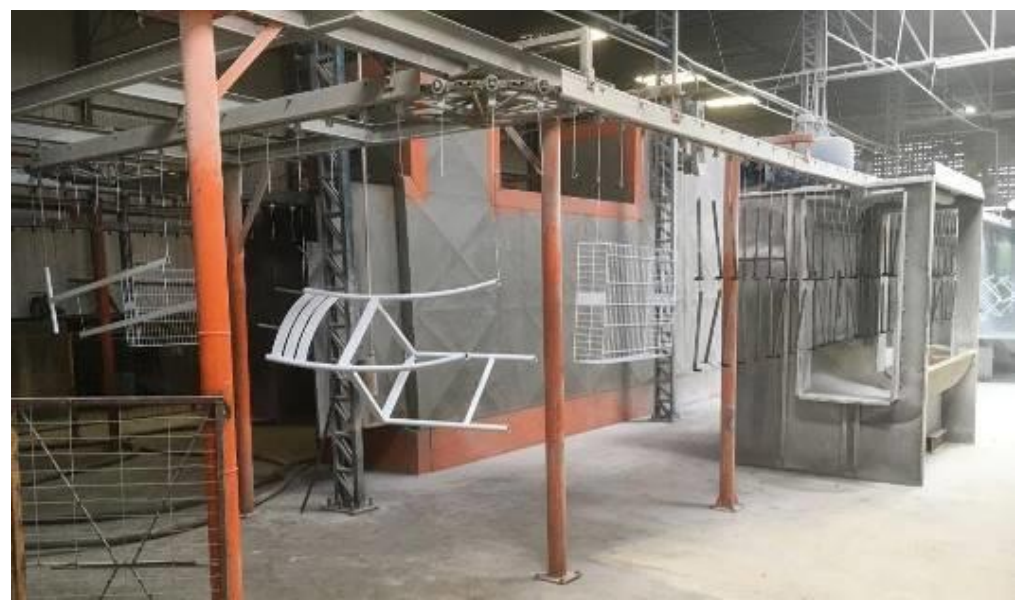

Fonte: Autor (2019)

Esse setor tem alocado 4 operadores para o seu funcionamento, onde dois deles são pintores e dois ficam responsáveis por tirar e colocar as peças nas gancheiras, ou dar algum acabamento necessário no produto. O cálculo foi feito em função de quantas gancheiras cada produto necessitaria para ser pendurados e consequentemente entrar na linha produtiva. Diante disso, e sabendo que cada vez que o produto gira leva em torno de 30 minutos para dar uma volta, e lembrando que ele gira duas vezes no processo, isso levaria 60 minutos para o produto ficar pintado, então foi preciso calcular o valor de cada gancheira individualmente e consequentemente quantas o cesto $\mathrm{n}^{\circ} 1$ iria precisar para ficar pendurado. É importante também saber que dependendo do produto, é possível pendurar um embaixo do outro, dobrando a capacidade de pintura. Nesse caso, não é possível utilizar a produção dessa forma e custo do Cesto $\mathrm{N}^{\circ} 1$ está definido abaixo:

Quadro 8 - Custo da mão de obra do Setor de Pintura

\begin{tabular}{|c|c|c|c|c|}
\hline PROCESSO & FUNCIONARIO & SEGUNDOS & HORAS/MÊS & CUSTO DO PROCESSO \\
\hline PINTURA & OPERADOR & 56,25 & 42,19 & $\mathrm{R} \$$ \\
\hline GANCHEIRAS UT & AS POR PROD. & 5 & 1 & 2 \\
\hline
\end{tabular}

\begin{tabular}{|r|cr|}
\hline \multicolumn{4}{|c|}{ CUSTO DE MÃO DE OBRA PINTURA } \\
\hline & R\$ & $1.881,56$ \\
\hline SUB-TOTAL & R\$ & $\mathbf{0 , 7 0}$ \\
\hline
\end{tabular}

Fonte: Autor (2019) 
A planilha pede no primeiro quadrante o número de gancheiras utilizadas, o segundo solicita se é possível colocar mais de um produto por gancho e o último solicita quantas vezes o produto gira no processo.

\subsubsection{Custo da Tinta no setor da Pintura}

Para calcular o gasto de tinta no produto, foi necessário saber quanto gasta por área pintada, sendo preciso entrar em contato com o fornecedor, que nos informou que a cada quilo de tinta utilizado, daria para pintar uma área equivalente a 7 metros quadrados. Com isso, é preciso calcular a área de superfície de contato do cesto para sistematizar o quanto de insumo é gasto. Foi informado o custo da tinta e com isso foi desenvolvido o cálculo da área de contato do produto, disponibilizado abaixo:

Quadro 9 - Custo da Tinta no Produto na Cor Branca

\begin{tabular}{|c|c|c|c|c|c|c|c|c|}
\hline \multicolumn{9}{|c|}{ PRECIFICACAO IINTA ARAME } \\
\hline DESCRIÇÃO & ARAME & RAIO (mm) & ALTURA $(\mathrm{mm})$ & PER (mm) & ÁREA $\left(\mathrm{mm}^{2}\right)$ & AREA $\left(\mathrm{m}^{2}\right)$ & QUANT.ARAME & TOTAL (mi) \\
\hline Al & 4.00 & 2,00 & 700 & 12,56 & 8804,56 & 0,00880456 & 9 & 0,07924 \\
\hline A.2 & 4.00 & 2,00 & 1280 & 12,56 & 16089,36 & 0,01608936 & 2 & 0,032218 \\
\hline $\mathrm{A}^{3}$ & 4.00 & 2,00 & 490 & 12,56 & 6166,96 & 0,00616696 & 2 & 0,01233 \\
\hline A4 & 2.10 & 1,05 & 820 & 6,594 & 5410,54185 & 0,005410542 & 24 & 0,12985 \\
\hline A5 & 2.10 & 1,05 & 180 & 6,594 & 1190,38185 & 0,001190382 & 32 & 0,03809 \\
\hline & & & & & TOTAL & 0,0376618 & 69 & 0,29170 \\
\hline & & & & & 40031 & \multicolumn{3}{|c|}{ CUSTO DA TINTA } \\
\hline & & & & & & COR & BRANCO & 15,36 \\
\hline & & & & & \multicolumn{3}{|c|}{ SUB-TOTAL } & RS \\
\hline
\end{tabular}

Fonte: Autor (2019)

\subsubsection{Custo do Setor da Embalagem}

O último setor da empresa fica responsável pela colocação de acessórios no produto, embalagem e direcionamento se o produto irá para estoque ou para expedição. Foi preciso desmembrar o custo em duas vertentes:

- Custo da Embalagem

- Custo da mão de obra da Embalagem

\subsubsection{Custo da Mão de Obra no setor da Embalagem}

A embalagem do produto é de forma manual, e não é necessário acessórios. A partir dessas informações, identificou-se o tempo que levaria para o cesto ser embalado, e descrito a seguir. 
Quadro 10 - Custo da mão de obra no setor de Embalagem

\begin{tabular}{|c|c|c|c|c|}
\hline PROCESSO & FUNCIONARIO & SEGUNDOS & HORAS/MÊS & CUSTO DO PROCESSO \\
\hline EMBALAGEM & OPERADOR & 220 & \begin{tabular}{ll|l}
305,56 & $\mathrm{RS}$ \\
\end{tabular} & $3.406,94$ \\
\hline & \multicolumn{4}{|c|}{ CUSTO DE MÃO DE OBRA EMBALAGEM } \\
\hline & & $\mathrm{R} \$$ & & $3.406,94$ \\
\hline \multicolumn{2}{|c|}{ SUB-TOTAL } & R\$ & & 0,68 \\
\hline
\end{tabular}

Fonte: Autor (2019)

\subsubsection{Custo da Embalagem}

O material utilizado para embalar os produtos na empresa é o plástico, ele é comprado no quilo, com isso, foi necessário pegar um produto embalado e pesá-lo para se saber a diferença do peso sem a embalagem e calcular em função do preço informado pelo setor de compras. Seguindo abaixo:

Quadro 11 - Custo da embalagem

\begin{tabular}{|c|c|c|c|c|c|c|}
\hline \multirow[b]{2}{*}{40031} & \multirow[b]{2}{*}{ EMBALAGEM } & \multirow{2}{*}{$\begin{array}{l}\mathrm{KG} \\
0,07\end{array}$} & \multicolumn{2}{|c|}{$\mathrm{KG} / \mathrm{RS}$} & \multicolumn{2}{|c|}{ TOTAL } \\
\hline & & & RS & 16,49 & RS & 1,15 \\
\hline & 40031 & \multicolumn{5}{|c|}{ CUSTO DE EMBALAGEM } \\
\hline & SUB-TOTA & & RS & & & 1,15 \\
\hline
\end{tabular}

Fonte: Autor (2019)

\subsubsection{Despesas Administrativas}

Por fim, foi necessário atribuir ao produto, o valor das despesas administrativas, que são as despesas que a empresa tem que não estão ligadas diretamente ao produto, ou que não participam diretamente no processo de transformação do insumo no Cesto $\mathrm{N}^{\circ} 1$, mas que são necessárias para o funcionamento da empresa. Podemos dividir elas em:

- Mão de obra: associado as pessoas e setores que a empresa dispõe, mas que não estão diretamente ligadas ao produto como o setor de Recursos Humanos, financeiro, departamento comercial, almoxarifado, motorista, encarregados que não participam ativamente da transformação dos produtos, mas que são responsáveis por direcionamento e comando das equipes, estagiários, além dos gerentes e o Pró-labore.

- Despesas Administrativas: Foi preciso mensurar o que a empresa gasta em média mensalmente levantando todas as despesas fixas e variáveis dos últimos doze meses e feito uma média para que o valor não fique tão discrepante.

- Tributos: Para os tributos foi definido apenas o IPTU da fábrica já que é o imóvel é próprio e não se necessita o pagamento de aluguel. 
Para o critério de rateio de toda a despesa administrativa foi necessário adotar parâmetros, onde no setor produtivo se tem quatro setores onde o produto pode-se passar pelos quatro ou só é necessário ser produzido em um dos setores, além de que após o produto acabado, ele pode seguir para o setor de galvanoplastia ou da pintura. Com isso não se podia atribuir todo o valor dessa despesa em cima apenas de um setor, e com isso o montante calculado é rateado a partir de quais os setores o produto é necessário passar, já que o Cesto $\mathrm{N}^{\circ} 1$ é calculado apenas no setor de Tela, e encaminhado diretamente ao setor de pintura, o critério de rateio foi adotado para todo o montante ser dividido por cinco e por fim, é novamente rateado pela produção estimada mensal. Com isso, o valor atribuído é ser identificado no quadro abaixo:

Quadro 12 - Despesas Administrativas

\begin{tabular}{|c|c|c|}
\hline \multicolumn{3}{|c|}{ DESPESAS ADMINISTRATIVAS } \\
\hline MÃO DE OBRA ADMINISTRATIVAS & R\$ & 2,67 \\
\hline DESPESAS ADMINISTRATIVAS & R\$ & 2,83 \\
\hline TRIBUTOS & R\$ & 0,02 \\
\hline TOTAL DESPESAS & R\$ & 5,52 \\
\hline
\end{tabular}

Fonte: Autor (2019)

\subsubsection{Impostos e Margem de Lucro}

Após o desenvolvimento de todos os custos do produto, foi necessário acrescentar a margem de lucro que a empresa desejava e o imposto pago para formação do preço final do item. Foi necessário solicitar ao contador da empresa o percentual de imposto pago a partir do regime da organização.

A margem de Lucro foi definida após reuniões e pesquisas de mercado feito pela empresa, adotando critérios como:

- Concorrentes;

- Valor agregado do produto;

- Rentabilidade;

- Qualidade.

Com isso, o gestor definiu uma margem de $30 \%$ de lucro para a maioria dos produtos, porém foi levantado uma questão de alguns produtos que detém de uma rotatividade maior, pudesse ser negociado essa margem. A partir disso, foi desenvolvido um resumo 
onde é entregue ao gerente comercial conseguindo analisar a capacidade produtiva da empresa, o custo do produto, o peso dele, além de identificar os percentuais adotando pela organização em relação a margem de lucro e o imposto pago, também é visualizado o valor atual do produto e que consegue sistematizar se ele tem lucro ou prejuízo e o percentual desse fator abordado, além de sugerir um novo preço de venda baseado na margem de lucro e o percentual de imposto que se é pago.

Quadro 13 - Informações dos custos do Cesto №1

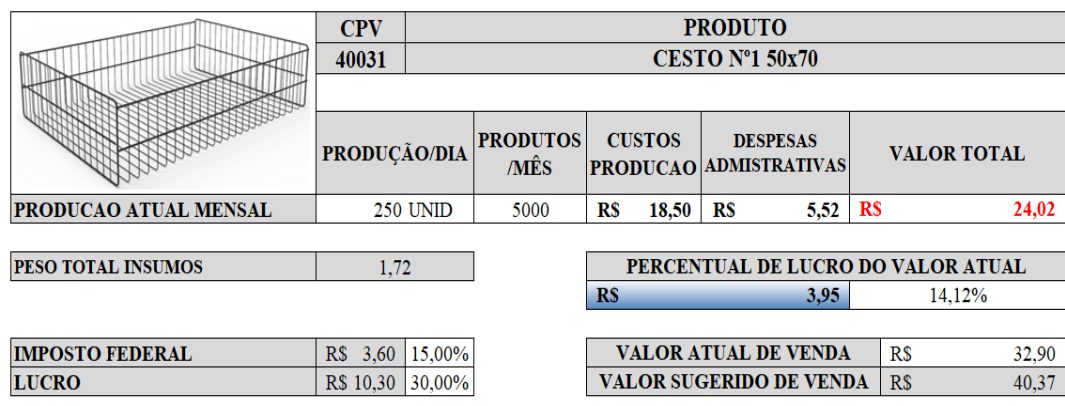

Fonte: Autor (2019)

A partir disso, foi possível notar que o Cesto $\mathrm{N}^{\mathrm{o}} 1$ não acarreta prejuízo, porém o percentual de lucro fica abaixo de $15 \%$, com isso, é necessário fazer um reajuste no valor do produto para que se consiga aumentar essa margem já que é um produto que tem demanda de mercado e é diferenciado na região por não existir tanta concorrência.

\section{CONSIDERAÇÕES FINAIS}

A partir do exemplo desenvolvido nesse artigo, foi possível criar um modelo para que fosse calculado o custo dos demais produtos e assim fazer uma análise se o setor de tela é realmente o setor que traz maior prejuízos para a empresa.

Ainda no setor de tela, foi proposto uma ação para se aumentar a produtividade do setor, já que como foi identificado no estudo, o processo de pontear e gabaritar tela formam o gargalo da produção, com isso foi sugerido que começasse se trabalhar com metas para aumentar o desempenho dos operados e consequentemente elevar a produtividade do setor, além de que é possível analisar o fluxo produtivo do produto para melhorar seu processo.

O setor de custos é essencial para empresa de qualquer segmento, pois além de se conhecer seu produto, é importante saber quanto realmente ele vale. É necessário desenvolver um mapa de todo o fluxo produtivo, para que seja possível mensurar os custos, além de identificação de possíveis desperdícios e gargalos no processo. 


\section{REFERÊNCIAS}

BARNES, R. M. Estudo de movimentos e de tempos: Projeto e medida do trabalho. São Paulo: Edgard

Blucher,

1977.

Disponível

em

http://www.repositorio.ufc.br/bitstream/riufc/13843/1/2011_eve_mvrodrigues_determinacao.pdf. Acesso em 30 de março de 2019.

BRUNI, A. L.; FAMÁ, R. Gestão de custos e formação de preços com aplicações na calculadora HP

12c e excel. 2. ed. São Paulo: Atlas, 2003. Disponível em http://www.abepro.org.br/biblioteca/ENEGEP2012_TN_STO_159_927_19985.pdf. Acessado em 10 de junho de 2019.

BUVINICH, Manuel Rojas; Apostila sobre custos Industriais. Departamento de Engenharia de Produção, UFPB. Disponível em http://abepro.org.br/biblioteca/TN_STO_208_234_27979.pdf. Acessado em 10 de junho de 2019.

KUNH, P.D.; FRANCISCO, A.C.; KOVALESKI, J.L. Aplicação e utilização do método unidade de esforço de produção (UEP) para análise gerencial e como ferramenta para o aumento da competitividade. Revista Produção Online. v.11, n. 3, p. 688- 706, jul./set., 2011.

MARTINS, E. Contabilidade de custos. 9. ed. São Paulo: Atlas, 2008. Disponível emhttp://www.abepro.org.br/biblioteca/ENEGEP2012_TN_STO_159_927_19985.pdf. Acessado em 10 de junho de 2019.

MOREIRA, D. A. Administração da produção e operações. São Paulo: Pioneira, 1993.Disponível em http://www.repositorio.ufc.br/bitstream/riufc/13843/1/2011_eve_mvrodrigues_determinacao.pdf. Acesso em 30 de março de 2019.

SLACK, Nigel; CHAMBERS, Stuart; JOHNSTON, Robert. Administração da produção. São Paulo: Atlas, 2002. pp.276-307. Disponível em http://www.abepro.org.br/biblioteca/TN_STP_238_377_34416.pdf Acesso em 28 de março de 2019.

RITZMAN, Larry P; KRAJEWSKI, Lee J. Administração da produção e operações. São Paulo: Prentice Hall, 2004. Disponível em http://www.abepro.org.br/biblioteca/TN_STP_238_377_34416.pdf Acesso em 28 de março de 2019.

WERNKE, R. Análise de custos e preços de venda: ênfase em aplicações e casos nacionais. São Paulo: Saraiva, $2005 . \quad$ Disponível em http://www.abepro.org.br/biblioteca/ENEGEP2012_TN_STO_159_927_19985.pdf. Acessado em 10 de junho de 2019. 